Arab World English Journal (AWEJ) Volume 12. Number.4 December 2021

DOI: https://dx.doi.org/10.24093/awej/vol12no4.18

Pp.259-278

\title{
Going beyond the Text: Interactional Competence in Reading Comprehension Class
}

\section{Sabria Jawhar}

Department of English, College of Science and Health Professions, King Saud bin Abdulaziz University for Health Sciences \& King Abdullah International Medical Research Center, Jeddah, Saudi Arabia. Correspondent Author: Jawhars@ksau-hs.edu.sa

\section{Sajjadllah Alhawsawi}

Department of English, College of Science and Health Professions, King Saud bin Abdulaziz University for Health Sciences \& King Abdullah International Medical Research Center, Riyadh,

\section{Saudi Arabia}

\section{Steve Walsh}

School of Education, Communication and Language Sciences, Newcastle University, Newcastle upon Tyne United Kingdom

Received: 7/24/2021

Accepted: 11/4/2021

Published: 12/15/2021

\section{Abstract}

Drawing on the principles underlying conversation analysis (CA), this paper is a single case analysis of interaction in an English as a foreign language (EFL) reading comprehension classroom in Saudi Arabia. It looks at learning from a sociocultural perspective and uses constructs from this theoretical perspective. It focuses on Classroom Interactional Competence (CIC) (Walsh, 2013), showing classroom interaction features that are considered CIC. The paper reflects how an understanding of the concept can lead to more dialogic, engaged learning environments. The paper also connects CIC to teachers' ability to manipulate simple classroom interactional resources to make the teaching process more effective. The paper demonstrates how teachers can induce CIC by utilizing interactional techniques, such as relaxing the mechanism and speed through which turns are taken or given, use of active listenership devices, extending wait time, and use of open-ended questions to expand topics under development. The paper argues that those techniques will help teachers, as evidenced from the cited examples, further enhance classroom participation so that it is convergent with their pedagogical goals. Finally, the paper has pedagogical implementations as it sheds light on techniques that help promote classroom interaction as an indication of learning among students with limited linguistic resources.

Keywords: conversation analysis, classroom interactional competence, EFL, higher education, reading comprehension

Cite as: Jawhar, S., Alhawsawi, S., \& Walsh. S. (2021). Going beyond the Text: Interactional Competence in Reading Comprehension Class. Arab World English Journal, 12 (4) 259-278. DOI: https://dx.doi.org/10.24093/awej/vol12no4.18 


\section{Introduction}

The past two decades have witnessed considerable growth in the literature on the importance of the social aspect of second language acquisition (SLA). At the same time, there has been a remarkable increase in polarisation among scientists. SLA researchers have been divided over the usefulness of conversation analysis (CA) as a methodology for studying SLA. Nevertheless, CA has gained a foothold in the field of SLA (Ortega, 2005) because of the perceived value it adds because it looks at learning via a social lens (Zuengler \& Miller, 2006) as well as looking at the micro details of the interactional organization.

On the other hand, SLA theories traditionally and due to their focus on the process whereby second language (L2) is learned have had an inherited cognitive orientation leading mainstream SLA researchers, such as Long (2006) and Gregg (2005), to consider SLA as a psycholinguistic process. However, inspired by Firth and Wagner's (1997) proposal, several researchers have challenged this orientation. The publication of Firth and Wagner's (1997) paper, which calls for a revision of the framework within which SLA is viewed, has led to a proliferation of studies that use CA within the field of SLA (Gardner \& Wagner, 2004; Richards \& Seedhouse, 2005; Kasper \& Wagner, 2011). In their 1997 (and a more recent version of the paper, 2007), Firth and Wagner emphasized the importance of the social and cultural aspects of L2 learning.

The following decades have witnessed a paradigm shift in the way mainstream SLA scholars view SLA. This paradigm shift is represented by several studies that emphasize the social and cultural aspects of SLA manifested in its use outside the classroom setting. Studies such as Kurhile (2006), Seedhouse (2004), and Nguyen (2011b), for example, brought to light the essential role of language use through talk-in-interaction in the process of L2 acquisition. And, subsequently, with the focus placed on spoken interaction came the questions about the nature of interactional competence and how it should be assessed in the classroom setting (Galaczi \& Taylor, 2018).

Interactional competence is one of the many aspects of SLA, in which conversation analysis (CA) has emerged as a powerful instrument and a well-established method of investigation. However, conversation analysts distinguish between IC as a constructed social activity and competence as cognitive knowledge that native speakers possess about their language, as defined by Chomsky (1965). CA, they have argued, is not a theory of language learning; thus, it cannot reflect what is occurring inside the interactants' minds (He, 2004).

Classroom interactional competence (CIC) is one of the many facets of IC. It is a term coined to define the "teachers' and learners' ability to use interaction as a tool for mediating and assisting learning" (Walsh, 2013, p.124). Though CIC takes different shapes and has different characteristics depending on the context, some features are common to all contexts. Nevertheless, teachers' CIC manifests itself in the shape of successful use of language that leads to the creation of better opportunities for learners to interact and display understanding in the classroom context. In other words, the teachers can make interactional decisions that serve their pedagogical goals and, at the same time, create 'space for learning' (Walsh \& Li, 2013). A more detailed discussion of CIC is presented in the next section. 
Galaczi \& Taylor (2018) noted a mismatch between the importance of interactional competence in SLA and the number of studies examining it in different instructional contexts. Their paper is a comprehensive review of the history of the term from a theoretical and empirical perspective.

This paper is an addition to the work that looks at CIC. It examines the EFL context through a sociocultural lens and demonstrates how CA can be used as a tool to illustrate the micro-organizational structure of conversation as an exceptional resource for second language pedagogy. It shows the micro details of the interactional practices that are deployed by teachers and students. It also demonstrates the different resources used by teachers to induce (CIC) and by students to display their knowledge of these resources. Learning, in this paper, is viewed as a social action that can be manifested and oriented towards. It is also assumed that learning is shaped or influenced by the extent of engagement of the students and their involvement in talkin-interaction (Walsh, 2012).

\section{Interactional competence Vs. classroom interactional competence}

The literature shows that many studies have looked at the role of interaction in shaping learning in the second language classroom (Markee, 2015; Seedhouse \& Walsh, 2010; Sert, 2015; Walsh, 2012, 2013; Waring, 2019). Interactional competence (IC) is among several classroom aspects that have generated increased interest from researchers in SLA during the past three decades. It also gained some momentum following the work of Kramsch (1986). For instance, Young's (1999) study, in which he proposed that IC is co-constructed and requires specific interactional events, is one of the best studies examining the construct of IC in SLA classrooms.

The use of CA to study interactional competence in different contexts has emphasized the uniqueness of each interactional context. It has also highlighted the importance of obtaining the required knowledge of the specifics of the interactional competence related to that context. This context-specific interactional competence knowledge might include anything from a new native speaker (L1) pharmacy intern learning how to interact with patients to L1 high school students learning new interactional competencies to interact with teachers, administrators, and higher authorities (Nguyen, 2011a). The literature has shown that IC can be understood as an umbrella under which different practices are included. It has also demonstrated the fluid nature of IC that changes and develops every time the learner is engaged in a conversation with an interactant who is more experienced (Kim, 2017; Pekarek Doehler \& Berger, 2016; Pekarek Doehler, Wagner, \& Gonzalez-Martinez, 2018; Sert \& Balaman, 2018).

Nevertheless, to understand the construct of IC more accurately, one should realize that people vary in their ability to communicate their ideas and make themselves understood. These differences are witnessed and reported in institutional settings and mundane conversations. However, when investigating an institutional setting, such as a classroom, the argument becomes more about the context-specific CIC than the general umbrella of IC. For instance, in the classroom setting, CIC is manifested in different patterns of interactions between the teachers and the learners and among the learners themselves. Some teachers, for instance, are more capable of engaging their learners in long and more meaningful interactional episodes than others. These teachers use different techniques and strategies to create "interactional space" (Walsh, 2006) for the learners and consequently increase their learning opportunities. 
Researchers agree on the role of teachers in helping their students utilize interactional resources, such as L1, to communicate in L2 while achieving their pedagogical goals. Students' orientation to co-construct meanings with the other interlocutor is usually witnessed through their efforts to display understanding and keep up with the interaction flow regardless of the adopted interactional resources.

Hall (1999) emphasized the importance of engaging in a conversation with an expert to learn interactional practices and asserted that this engagement provides guidance for the novice learner. In a classroom setting, the teachers play the role of the expert from whom they get guidance concerning interactional practices. Young (1999), one of the researchers who discussed IC in a classroom context, argued for the importance of the interactants' engagement in meaning construction. He stated that L2 knowledge is co-constructed and that IC is not a mental property in the learner's mind. In fact, he confirmed that IC is the product of the interactive process of talk-in-interaction.

Similarly, Walsh (2013) places interaction at the heart of learning, adding that CIC is mainly about how the interactants in the classroom manage the communication. To him, a teacher who demonstrates CIC uses the language in a way that is both convergent to his pedagogic agenda and, at the same time, is appropriate to the learners. Based on this argument, any evidence for CIC should reflect the relationship between the pedagogical agenda and the language used to implement it. In their discussion of CIC features, Moorhouse et al. (2021) added that it creates "space for learning." They argued that the space for learning could be created by "increasing wait-time, promoting extended learner turns and allowing planning time. By affording learners space, they are better able to contribute to the process of co-constructing meanings" (Moorhouse et al.,2021,p.3). It also, they added, helps in shaping the learners' contribution and helping them to express themselves.

This paper is in line with the previously mentioned work that associates classroom interactional competence with engagement. It argues for the teachers' ability to induce better interactional competence if, and only if, they deliberately use interactional techniques that encourage their students to engage in extended conversations that lead to the achievement of the teacher's pedagogical agenda. Teachers, we argue, can play a vital role in providing their students with opportunities through which they can co-construct and negotiate meaning. They can do this by building on their students' L1 interactional competencies. They can also overtly expose the students to various L2 interactional techniques appropriate to the specific context in which they are involved. As Nguyen (2011b) stated, "participation itself is the target of learning: A second language learner needs to develop the specific interactional resources to participate in conversation with the target language" (Nguyen, 2011b, p. 38).

\section{Data and Methodology Participants}

The data was collected in the year 2010 from a language institute in Saudi Arabia. The students were all native speakers of Arabic, as was the teacher. The students were studying English as part of their foundation program, after which they would attend university and choose their specialties based on their GPAs. The participants were 26 learners whose ages ranged 
between 19 and 21. The students' level of proficiency is characterized as lower intermediate, and they are grouped based on the result of their placement test.

\section{Procedure}

While the data is part of a bigger corpus of 30 hours of EFL teaching, the segment used for this paper is a teaching session of 120 minutes that stood out during the transcription process as a unique example of CIC. Of those 120 minutes of interaction, the focus was only on the phase during which the teacher shifted the focus from book-based activities to the general discussion of a topic related to the students' reading. During this phase of the lesson, the teacher asked the students to display an understanding of what they had learned from the text. The students were expected to use as much vocabulary as possible from that which they had just been taught. The teacher's initial question was about the students' opinion regarding the current lifestyle of young people and how this differs from the lifestyle of previous generations. The question was asked to test the students' ability to use the newly introduced vocabulary in an unfamiliar context, going beyond the text in the book (Appendix A). Typically, the teacher assesses the appropriacy of the provided answer in relation to the ongoing activity.

\section{Data Analysis}

The data were transcribed using conventions adapted from Paul ten Have (2007). A turnby-turn analysis was conducted to allocate the different interactional techniques used by the teacher and students. It is essential to mention that the data is a single case that the researchers believe is an excellent example of CIC in EFL classrooms.

\section{Results}

In this section, we will present different excerpts taken from a reading comprehension classroom. However, the focus is mainly on the section of the lesson during which the teacher shifted the focus from the reading material to questions related to the students' real lives in order to assess their comprehension of the passage as well as their ability to use the vocabulary they had just learned in a new and unfamiliar context (See section 3.2).

Before the extract, the teacher introduced a reading passage about the change in the dynamics of lifestyles in the USA over the past three decades. Following this, she started to ask questions related to the students' own experiences. This sequence is used as a topic initiation technique (Schegloff \& Sack, 1973) to get the students engaged and mark the new phase of the lesson.

\section{Excerpt (1)}

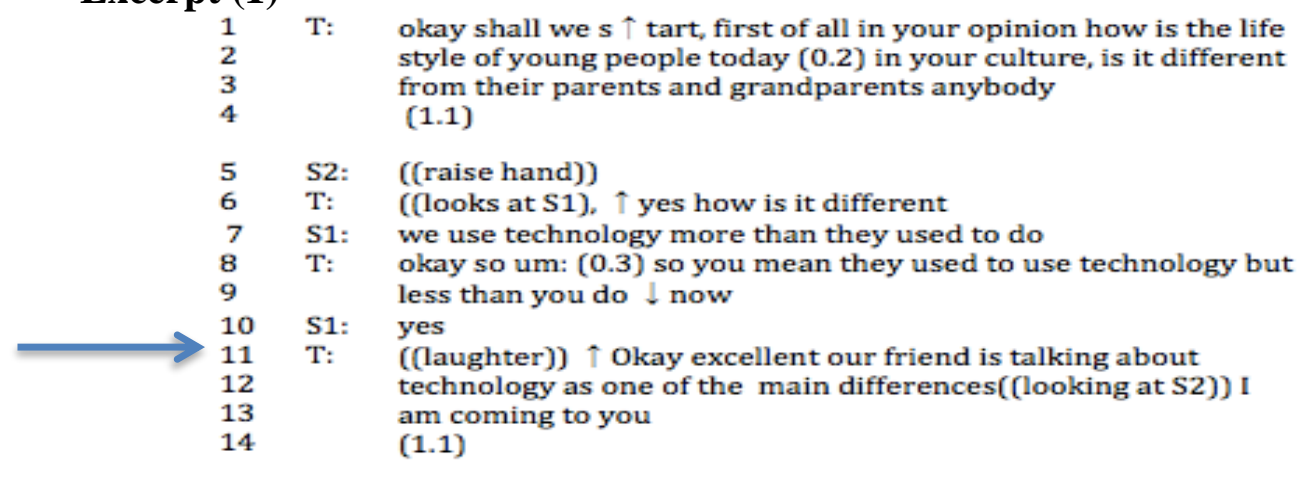


In this excerpt, the teacher asks the students an open-ended question about their opinion regarding the current lifestyles of young people and how this differs from the lifestyles of previous generations (lines 1-3). The teacher follows this with a relatively long pause (1.1) to give the students sufficient time to think about answers and establish a connection between what they have read in the book and their real lives, i.e., her pedagogical objective. Although the teacher directs her question to the entire class, S2 shows an orientation to answer by raising her hand to attract the teacher's attention. However, the teacher moves towards S1 and establishes a mutual gaze, followed by a short response token "yes" to locate the next speaker, and repeats part of her question as a reminder to the student. S1 takes the floor and produces a multi-unit turn using comparison devices to display knowledge of the purpose of the question, which is a comparison of her generation and the previous one.

The teacher uses "okay" to acknowledge the student's answer and follows that by a word search device "um" followed by a micro pause $(0.3)$. This indicates that the teacher hesitates regarding whether to accept or reject the answer. She follows this by a confirmation request using the phrase "do you mean X" (Mackey \& Goo, 2013). This kind of phrase is usually used in the second pair, yet the teacher uses it in the third part of the triadic IRE sequence. By so doing, the teacher is giving the student enough room to confirm and, possibly, to produce a further explanation of her answer. However, the student perceives the confirmation request as a yes/ no question and offers a single-unit turn using "yes" as an answer (line 10).

The teacher follows with laughter to ease any tension that might have resulted from the delay of the evaluation part of the initial sequence or from the student's indication of minimal involvement (Nesi, 2012). She follows the evaluation "excellent" by a reformulation of part of the student's answer. She announces the closure of the sequence by looking at S2, who has also shown an orientation towards participation.

In this excerpt, we notice the teacher's use of several interactional techniques, such as extending the wait time to allow the student to rehearse the answer, paraphrasing the student's response, and then prefacing it with the phrase "do you mean $X$ " in order to request confirmation. Though simple IC techniques, they result in the next students showing a willingness to participate, as can be seen in the following excerpt. In excerpt (2), the teacher approaches S2, who shows orientation towards participation and uses a short response "yes" to choose the next speaker.

\section{Excerpt (2)}

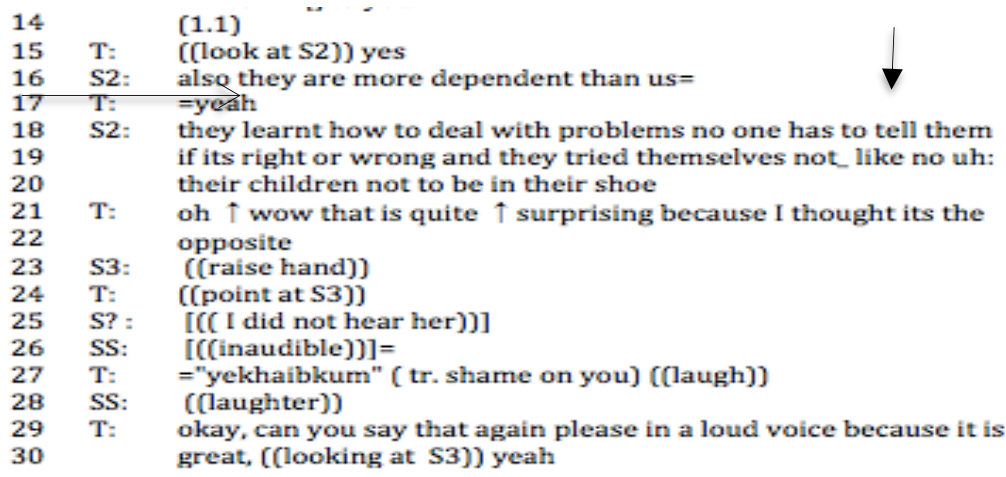


Following the closure of the sequence with S1 (excerpt 1), the teacher also establishes a mutual gaze with S2, who shows orientation towards participation. In addition, she gives S2 some time to rehearse her answer (line 14) (Walsh, 2012) while she moves towards her. As in the previous excerpt, the teacher, who is mainly responsible for managing the turns by allocating who speaks next, tends to give the floor only to those students who show an orientation towards participation (Reddington, 2018).

S2 (line 16) builds on her friend's answer using the conjunction "also." S2 also shows an understanding of the teacher's request for comparison by using a comparative form. The student marks her TRP (Transition Relevance Place: the point in any interaction where there is the potential for another speaker to take a turn at the talk) through the use of a descending tone. However, the teacher latches onto S2 contribution using a short response token "yeah" to reflect percipience and active listenership (McCarthy, 2003).

The student perceives the teacher's use of the short response token as a request to extend her explanation. This is shown in the next turn, in which the student produces a multi-unit turn involving an unprompted explanation. We also notice the student's orientation to linguistic accuracy, as she abandons part of her turn and uses a new one to make herself more understandable "not_like no uh::" The teacher (lines 21-22) expresses her surprise using the newsmaker device "oh," following it with a justification of why she was surprised "because I thought it was the opposite."

Because the teacher seems to have established a systematic way of managing the turns, i.e., trajectory, that includes the students who show orientation towards participation followed by her allocation of the turn, she mistakenly allocates the turn to S3, expecting an addition to the ongoing discussion.

However, to the teacher's surprise, an unidentified student expresses difficulty in hearing the ongoing talk. The teacher (line 27) overtly displays her confusion as to why S3 raises her hand in the absence of a response, but she also uses the incident to introduce playfulness and create a sense of fun by using her L1 followed by laughter (Jawhar, 2018). In line (28), the class reciprocates by laughing out loud.

Following this, the teacher retakes control of the turn using the discourse marker "okay" to mark the end of the playfulness and asks $\mathrm{S} 2$ to repeat her answer, adding a justification of why she should do so: "because it is great." The teacher's praise of S2's answer encourages the student to produce a more complex and carefully designed turn in which fewer grammatical mistakes occur. This excerpt shows us how the teacher's use of active listenership device and display of complete engagement in the conversation resulted in a more complex turn and display of more sophisticated interactional competence. We also notice quite a fast-paced interaction with a couple of incidents where latching takes place.

In the next segment of the episode, excerpts (3), S2 responds to the teachers' request to repeat her answer (excerpt 2). However, S2 pauses after the first part of her participation, but is encouraged by the teacher, who again uses a short response token "aha" to indicate understanding and a desire for the student to continue. Finally, the teacher rewards S2 by 
recasting her answer and using it as an initiator of a new subtopic. She asks the students if they agree with S2's proposition.

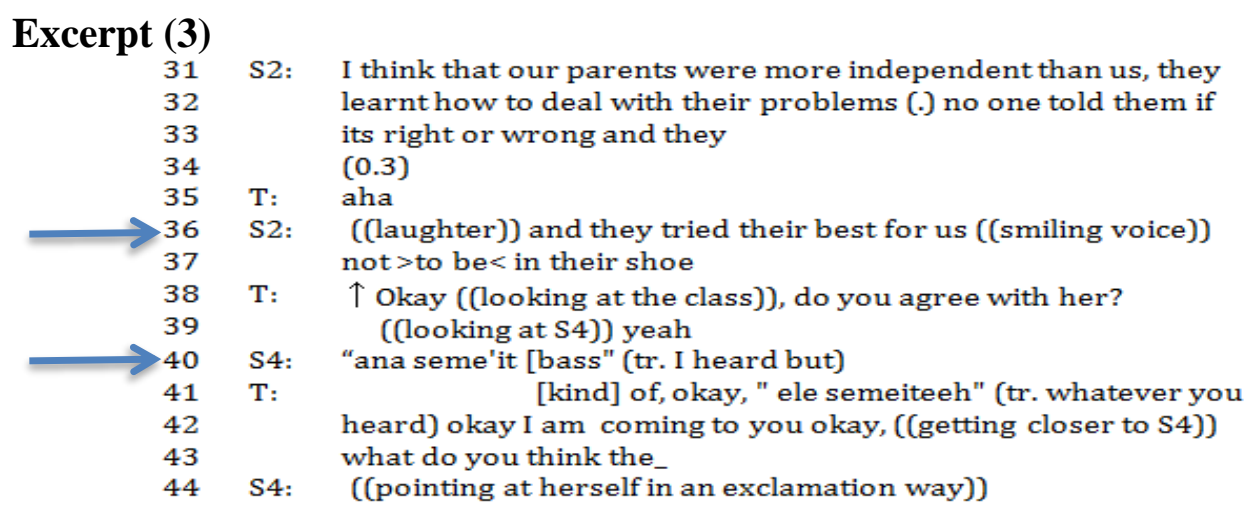

The teacher builds on S2's answer in this excerpt and uses it as a topic for the newly initiated sequence (line 38). S4 displays what is understood by the teacher as an orientation towards participation. The teacher establishes mutual gaze (Goodwin,1980) and allocates the turn using "yeah" in a single unit turn after stepping closer to S4. S4 is not ready to take the turn; therefore, she starts her turn with an L1 justification for her lack of participation. She expresses trouble in the communication and tells the teacher that she did not hear what was said earlier.

Nevertheless, the teacher does not allow her to avoid her turn and insists on receiving an answer, even though S4 did not hear the entire conversation. This excerpt is yet another example of the teacher's use of a short response token as an acknowledgment of the student's extended participation. It also shows the effects of the deployment of the short response directly after the student's second turn response (i.e., a possible TRP) (Ford \& Thompson, 1996). In addition, since the teacher does not deploy the token as a 'stand-alone' but provides more talk, she takes over speakership and does not display passive recipiency in the sense that she passes up an opportunity to take a fuller turn (Gardner, 2001; Jefferson, 1984)

In excerpt (4), the teacher gives the floor to S4 using the short response "yeah" as a freestanding device in an invitation for her to participate.

\section{Excerpt (4)}

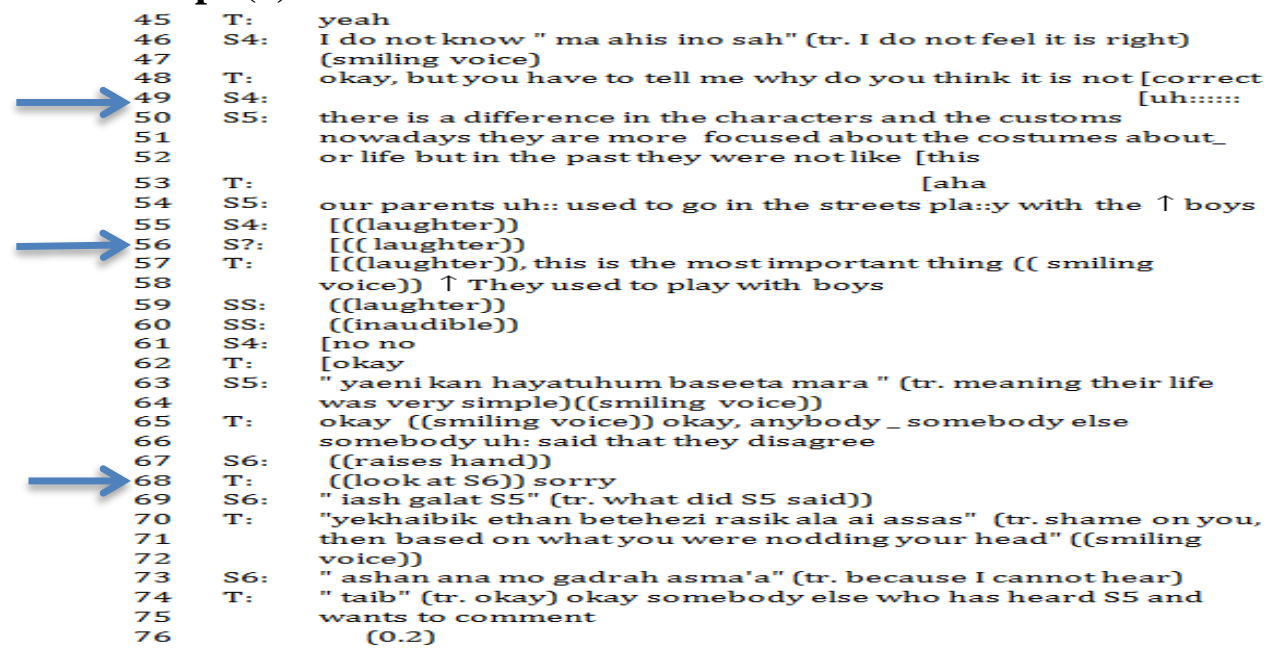


S4 does not seem to be ready for the turn to be allocated to her; thus, she displays a claim of insufficient knowledge (Sert \& Walsh, 2013) by using the phrase "I don't know" followed by a justification in a smiling voice using her L1 "I don't feel it is right" (line 46). The teacher uses the short response device "okay" to display acknowledgment, but follows the acknowledgment with a request for a further explanation using L2, "but you have to tell me why you think it is not correct." The student overlaps with the teacher's TRP using a prolonged explicit word-search device "uh::::::" (Brouwer, 2003). S5 takes an unsolicited turn and offers an answer that is perceived as funny by the teacher and some other classmates, such as S4 and another unidentified student.

S5 touches upon the socially sensitive topic of mixing between the genders. However, the rest of the class refrains from participating in the laughter until they receive a signal from the teacher, who laughs and treats the suggested subtopic as a source of amusement (lines 57-58). S4 realizes the sensitivity of the topic and overlaps with the teacher in an attempt to take the floor. She only manages to take the floor when the teacher gives it up and uses the discourse marker "okay" in what is understood as an allocation of the turn. S5 takes the floor (line 63-64) and explains her previous answer, but uses L1.

The teacher displays understanding of the problem but, at the same time, shifts the topic by looking for someone else with an opposing idea: "somebody uh:: said they disagree." Another conversational difficulty occurs when S6 raises her hand in a move that the teacher understands as an orientation towards participation when, in fact, it is nothing but a way of expressing difficulty hearing. Once again, the teacher treats the communication breakdown as a source of playfulness and uses the L1 to create laughter. S6 understands the teacher's disappointment and offers a justification for why she did not meet the teacher's expectations, and produces an answer (line 73). Following this, the teacher expresses understanding and invites participation, but only from those who have heard the entire conversation.

This excerpt is an example of how the teacher deals with trouble in communication by using L1 as a source of humor, and accepting the student's participation, using L1, for the sake of prolonging the exchange. A further example is her use of open-end questions to elicit more contributions.

Excerpt (4) is a clear example of how the teacher managed to encourage the students to engage in the ongoing topic by using interactional resources such as acknowledgment, active listenership devices and request for an explanation. Excerpt (5) is a continuation of (4).

\section{Excerpt (5)}

$\begin{array}{lll}76 & & (0.2) \\ 77 & \text { S7: } & ((\text { raise hand)) } \\ 78 & \text { T: } & \text { ((look at S7)) do you want to comment on what S5 has said, } \\ 79 & \text { S7: } & \text { yes } \\ 80 & \text { T: } & \text { yes what [do } \\ 81 & \text { S7: } & \text { [I think the opposite }= \\ 82 & \text { T: } & \text { = You think the opposite? } \\ 83 & \text { S7: } & \text { yeah } \\ 84 & \text { T: } & \text { okay } \\ 85 & \text { S7: } & \text { I think we are more independent because our parents when } \\ 86 & & \text { they want to learn something they have to depend on } \\ 87 & & \text { someone else to teach them } \\ 88 & \text { T: } & \text { =aha } \\ 89 & \text { S7: } & \text { but we can teach } \downarrow \text { ourselves }\end{array}$


Following a micro pause by the teacher (0.2), S7 shows an orientation to answer, but this time, the teacher wants to avoid misunderstandings or communication difficulties. The teacher establishes intersubjectivity by asking the student whether she is raising her hand to offer an answer or for other reasons. S7 confirms her desire to participate using a short response token "yes" in the second position of a question/answer adjacency pair. The teacher approves the participation and gives the student the floor. The student starts her multi-unit turn with the expression "I think" to indicate having lesser epistemic access to the topic, as well as her evaluation of a former proposition (Heinemann, 2008). The teacher latches onto the student using an active listenership device, "aha," to encourage her to continue producing more talk. The student (line 89) maintains the floor longer by using a justifying subordinating grammatical conjunction "but" that indicates that more talk is coming.

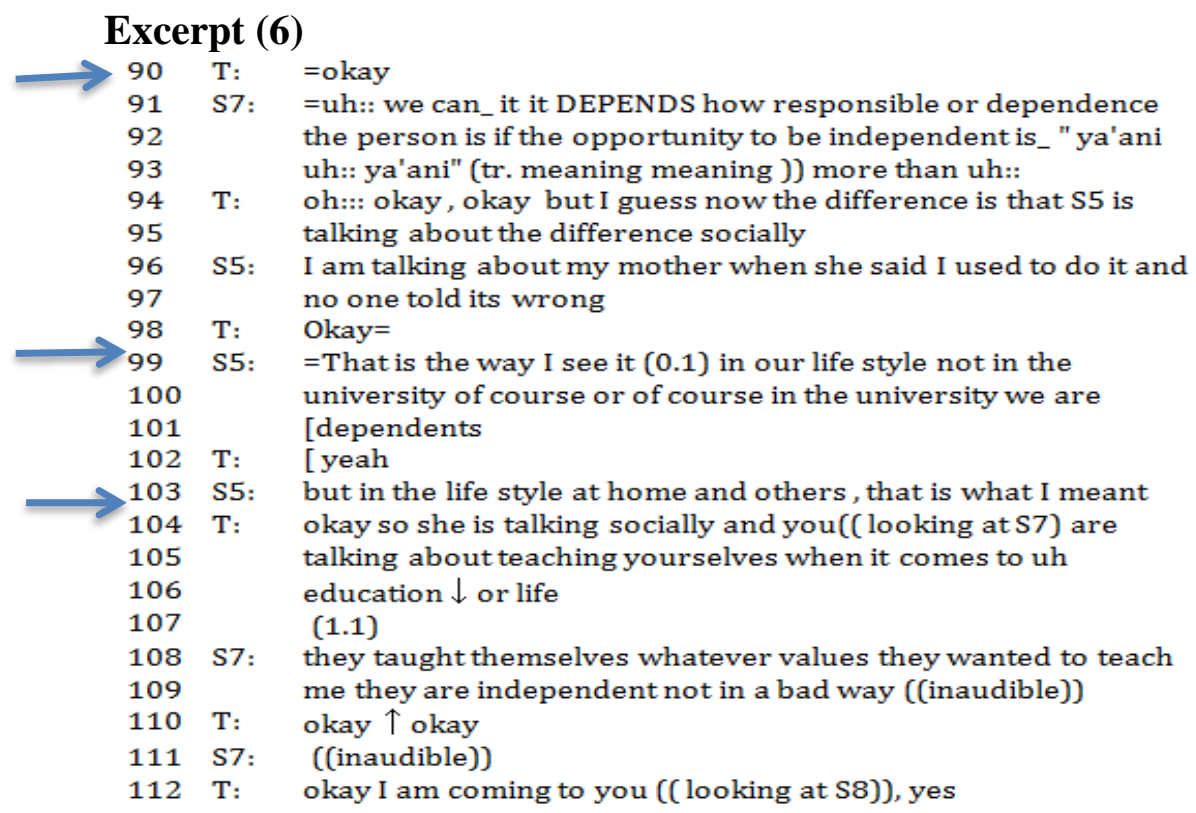

The teacher again latches onto the student (line 90), using a single-unit turn "okay" to indicate acknowledgment and, at the same time, to hand over the turn to the same student. By so doing, the teacher is creating more interactional space for the student and indicating a request to pursue the topic. This interactional strategy results in another complex multi-unit turn in which the student feels at liberty to introduce a new subtopic, as she compares the difference between being socially dependent and being academically dependent. She uses different devices to maintain the turn and express complex ideas, which indicates orientation towards interaction and the communication of ideas.

Despite the grammatical mistakes in the S(7) turn, the teacher follows a "let it pass" strategy (Firth, 1996), ignoring the error to ensure that the student interacts. In lines (94-95), the teacher uses a stretched newsmaker device "oh:::" to display change-of-state, followed by double discourse markers "okay okay" to show understanding. However, to maintain the turn and announce that more talk is forthcoming, the teacher uses the subordinate grammatical conjunction "but." The teacher summarises what S5 has said "the difference is that S5 is talking about the difference socially". In line (96), S5 takes the floor and offers an unsolicited explanation of what she had said earlier. 
The teacher follows with a single unit "okay" that indicates acknowledgment and hands the turn back to the student. The teacher does not make any attempt to claim the turn. S5 latches onto the teacher's turn (line 99) and further explains what she means. The teacher only overlaps to display active listenership "yeah". S5 continues with yet another multi-unit turn by using the appositional device "but". Due to the misunderstanding that resulted from the emerging subtopic of being dependent versus independent at school and home, the students continue their attempts to justify what they meant. This is strong evidence of the students' orientation towards interactional competence and the establishment of mutual understanding. The teacher takes the floor (line 104) and offers a solution to the problems in the communication by paraphrasing what each of the students meant. Following a relatively long pause by the teacher (1.1), S7 retakes the floor and adds a further explanation of what she meant. The teacher uses a framing move "okay, okay" to display an understanding of the source of the problem and to show that she is prepared to move to the next phase or the next person.

The following excerpt (7) is evidence of the teacher's success in creating an interactional space that resulted in more willingness to participate in the ongoing talk and, consequently, better interactional competence.

\section{Excerpt (7)}

$112 \mathrm{~T}$ : okay I am coming to you (( looking at S8)), yes

113 S8: (( inaudible)) I do something wrong my mother keeps telling

114 me I used to do the same thing and I don't want you to do it so

115 may be it can cause me something bad so she keeps telling me

116 that don't do that do this "and do this

$117 \mathrm{~T}:$ and you think this is good or $\uparrow$ bad=

118 S8: $={ }^{\circ} \operatorname{good}^{\circ}$

119 T: $\uparrow \operatorname{good}$

120 S8: yes

121 T: its good (( looking at the class) so she thinks that her mam's

122 advice is good for her

In line (111), S8 shows her orientation towards participation. The teacher announces that she is moving towards her in a routine that the class understands as allocation of the next speaker. The nonverbal orientation of the teacher regarding the acceptance of the students' participation is usually accompanied using the short response device "yes" to allocate the next speaker. S8 responds by producing an extended and complex turn (lines 113-116). The teacher does not attempt to interrupt or take the floor. She waits until the student reaches a TRP and uses "and" to build on the student's previous response by asking her about her opinion regarding her mother's behavior and whether it is good or bad. The student latches onto the teacher's turn and whispers, "good".

The teacher expresses difficulty in hearing what the student has said by repeating the source of the problem with a rising intonation to require confirmation of having heard the answer correctly. S8 confirms this in line (120) using a single-unit turn consisting of the short response token "yes". The teacher repeats S8's answer to the rest of the class in what is understood, in this context, as positive feedback and an indication of the end of the sequence.

This excerpt shows how the teacher's minimum interruption of the students' turns, as witnessed in excerpts (6), encouraged S8 to show orientation towards participation despite her 
limited linguistics resources. Also, the teacher showed orientation towards meaning rather than form by overlooking the grammatical mistakes and focusing on extending the conversation (line 117).

In the following excerpt, we see another example of an exchange between the teacher and the student that led not only to encourage the student to use L2, but also to show orientation to communication beyond the teacher's original request.

\section{Excerpt (8)}

123 S9: (( raising her hand))

$124 \mathrm{~T}$ : yeah (( looking at S9)

125 S9: "momken agool be alarabi" ( tr. can I say it in Arabic)

126 T: No: try in English

127 S9: I think Um:: in the past the parents was only teaching the

128 children $=$

129 T: aha

130 S9: so they raise them but now the parents uh: they um they raise

131 you but also you raise yourslef=

$132 \mathrm{~T}: \quad=$ okay

133 S9: about what you see and what you experience and so on

$134 \mathrm{~T}$ : okay so there is an additional elment now to the way you

Following the teacher's closure of the sequence in line (122), S9 displays an orientation towards participation by raising her hand. The teacher establishes a mutual gaze with S9 and uses "yeah" to allocate the turn. S9 then asks the teacher for permission to participate using the L1, but the teacher refuses to grant her permission and asks her to try in English. The teacher's refusal results in a downgraded response prefaced by the phrase "I think" to show the student's epistemic stance.

The student follows this by a prolonged searching for words device "Um::" followed by a complete turn. The teacher waits until the student reaches a TRP and latches onto her by using active listenership device, "aha", which indicates a request for the student to continue her talk. The student retakes the turn and adds further illustration. The teacher latches onto S9 using "okay" in a single-unit turn to display acknowledgment. S9 retakes the floor for the third time and finishes her contribution by stating that nowadays, children raise themselves through their experiences. The teacher indicates understanding using "okay" in lines (134-136) as acknowledgment, and then reformulates the student's answer. She then uses a question format to initiate a new subsequence by directing the question to the entire class, asking them for their opinions and whether they agree with S9 (Extract 9, lines 135-136).

\section{Except (9)}

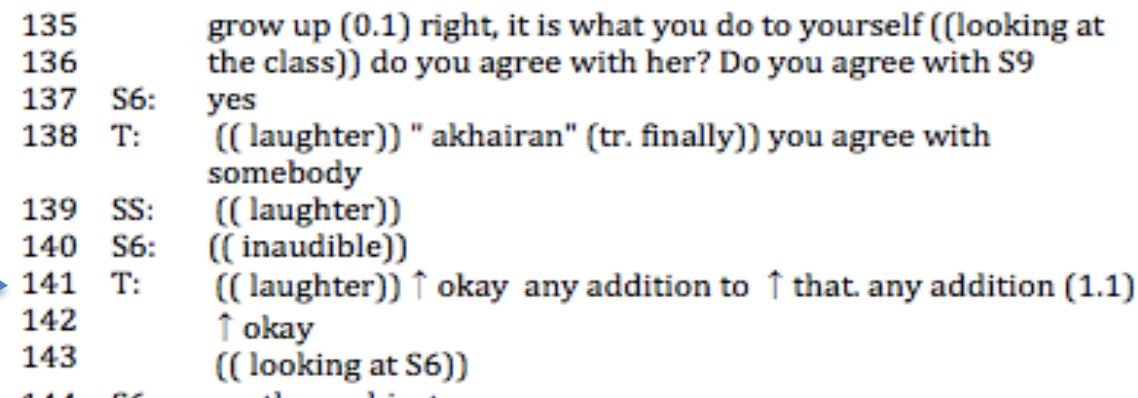


In the next excerpt, S6 tries to say something that is not audible, and the teacher acknowledges S6's contribution and initiates a new sequence by asking for an addition to what S6 has said. S6 does not give up her attempt to contribute, as she raises her hand in a request to be given the floor. The teacher establishes a mutual gaze with her and allocates the turn. S6, as can be seen in Excerpt (10), asks for permission to initiate a side sequence by suggesting a different topic, "another subject" (line 144).

Excerpt (10)

144 S6: another subject

145 T: (( smiling voice)) another subject sure go ahead

146 S6: (( inaudbile))

$147 \mathrm{~T}$ : yeah okay financially, money, yeah thank you

148 S10: "can fe harah we ketha" (tr. there was neighborhood and so

149 on)

150 T: ((laughter)) " harah we ketha ma tenfa'a fe alengleezi" ( $t$ tr.

151 neighborhood and so on this can not be said in English)

152 SS: (( laughter))

153 S10: "eywah ma tenfa'a" (tr. yes it can not))

154 (( smiling voice))

155 S?: (( laughter)) (( inaudible))

156 T: there is no " harah" (tr. neighborhood)) and ((laughter)) no "

157 eyyal" (tr. Boys) in the " harah" (tr. neighborhood))

158 S10: Ya'ani momken tokhreji aye wagt adi alwatha'a ya'ani adi

159 [daheen ya'ani la troohi la tokhreji (tr. meaning you can go out

160 anytime and anywhere it was okay now you, i mean, don't go

161 S11: "hata ma'a alawalad kan adi (tr. even with boys it was okay)

162 T: aha

163 S11: [" da heen after asahwah sar mafee" (tr. now after the

164 wakening (Islamic revolution) there is no trust)

165 S12: [" can fee thigah marah ziyadah" (tr. there was too much trust)

166 T: "thigah" (tr. trust), yeah

167 S11: " ba'ad alsahwah sar mafee (tr. after the wakening (Islamic

168 revolution) there is not anymore)

169 T: "ele heyyah" (tr. that is what)

170 S11: "ele ya'ani_can ya'ani_can yeshoofo_fe al past can fe _

171 makanow meltazemeen be aladat we altagaleed. Mo aladat we

172 altagaleed zai mathalan daheen mamnoo'a alikhtilat we kitha

173 ya'ani kanat hayatuhum adyah ba'ad ma jat alsahwah sarow

174 yegoolo mamnoo'a al|ikhtilat

(tr. Meaning_there was_ they used to see_ in the past there was_they were not sticking to customs and tradition. Not customs and tradition, like for example religion. Mingling was forbidden and so on. Meaning their life was normal. After the

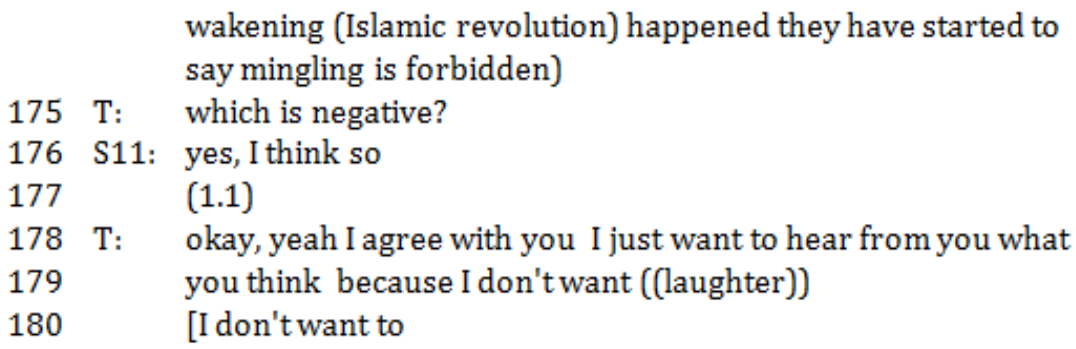

The teacher gives the green light to S6 to introduce a new topic (line 145), and S6 adds something that is not audible. The teacher (line 147) acknowledges S6's contribution, but concludes the sequence without further explanation concerning the newly introduced topic, which indicates that she treats the newly introduced topic as irrelevant. S10 waits for the first possible TRP and takes the floor. However, she uses her L1 to initiate a new sequence and 
introduces a new subtopic related to social life and neighborhoods. The teacher treats the contribution as humorous and repeats it, asking if the same answer can be given using English instead of the L1 (lines 150-151). The students understand the teacher's use of the L1 as humorous and reciprocate with laughter. S10 (line 148) treats the teacher's humor as a question and responds by confirming that she cannot answer in English: "yes I can not".

The teacher (line 152) maintains the humor and uses code-switching in a turn consisting of Arabic and English. The teacher's creative but amusing use of both languages was perceived as a green light to continue the communication in the L1(Jawhar, 2018). Therefore, S10 retook the floor and produced an extended turn in the L1 in which she offered an explanation of what she meant in line (148). S11 waits until S10 reaches a TRP and takes the floor to add to the discussion. The teacher (line 162) uses a newsmaker device in a single-unit turn "aha" without claiming the floor. By so doing, the teacher opens a new interactional space for S11 to elaborate on her answer, although still using the L1. This also shows the teacher's and the students' orientation towards communication rather than towards accuracy. The teacher is eager to keep the communication going and give the students a chance to be heard, even if this means using the L1. S12 takes the floor once S11 reaches a TRP and adds to the ongoing topic (line 165). The teacher repeats part of S12's answer in what is understood as a request for clarification; however, S11 takes the floor and confirms what S12 has said: "after the wakening, there is not any more".

The teacher (line 169) reformulates her question, asking overtly about what S11 means. S11 responds this time with an extended multi-unit turn in which she explains what she meant using different interactional competencies. For instance, she produces three false starts in which she interrupts her turn and makes a new start. She then uses self-initiated repair and reformulates her sentence, supporting her argument with an example. The teacher checks for understanding using a Wh-question with a rising intonation (line 175). The student responds to the teacher's question with a degraded answer prefaced by the short response token "yes". A lengthy pause (1.1) follows to give the student more time to elaborate, but when no further explanation is given, the teacher takes the floor and expresses acknowledgment and agreement with the student's proposition. However, the teacher offers an explanation of the relatively long pause, adding that she just wanted to hear the opinion coming from the student herself.

This excerpt is an excellent example of the teacher's creative use of L1, topic management, active listenership devices, and confirmation request as interactional resources. It shows how the use of such simple techniques resulted in a multi-unit turn with a display of more advanced interactional competencies.

\section{Discussion}

In this section, we will discuss the primary interactional resources used by the teacher and how they led to increased engagement on the part of the students. The focus will mainly be on classroom interactional competence, as discussed by Walsh (2012). We will discuss the main interactional features such as the turn-taking process, topic management, repair, use of the L1, and extended waiting time, emphasizing how the teacher managed them. The argument, as mentioned earlier, is that by utilizing these interactional strategies, the teacher can encourage the students to be more involved in the ongoing conversation and induce better interactional competencies. 


\section{Turn-taking}

In this class, as we have seen, although the turns are mainly allocated by the teacher, there are several instances of the turns being managed cooperatively in such a way that the students are free to take a turn whenever they wish. The teacher only allocates a turn to a particular student when she notices verbal or non-verbal orientation towards participation. In the few instances in which the teacher practices her traditional institutional role and allocates the next turn to a student who has not shown readiness to take it, confusion results, and the students sometimes show unwillingness to participate.

The students keep the floor using extended turns, and the teacher does not attempt to claim the turn. On the contrary, most of the time, the teacher uses short response tokens that indicate active listenership, which the students understand as a request for further illustration.

We have also seen examples in which the students take unsolicited turns, and the teacher understands these as further contributions. Because of her orientation towards communication and increased classroom interaction, the teacher submits and yields the turn to the student. This interactional technique results in extended turns consisting of complex ideas, which signifies advanced interactional competence in L2 (Young,2013). The students' ability to maneuver the turn-taking system is excellent proof of the teacher's success in inducing better interactional competence. Nevertheless, this skill would not be possible without the teacher giving up her tight control over the mechanism of turn taking and her right to interrupt and control the amount of time allocated to each student.

We also see many overlaps between the teacher's turns and those of the students. The overlap sometimes culminates in one party yielding the floor to the original speaker. However, on other occasions, mainly when the original speaker is the teacher, the overlap does not give the student the right to take the turn away from the teacher. However, the students in this class are attentive to the teacher's talk as they are oriented towards TRP when producing a response in an overlapping position. The students in this data show a high degree of interactional competence in terms of their understanding of the TRP. They display their understanding using latching and overlaps. Between-turns gaps are rarely witnessed, and the conversation seems to be characterized by a rapid pace.

\section{Active listenership}

The teacher's extensive use of active listenership devices has succeeded in eliciting complex multi-unit turns, with more than one idea expressed by the students. Sacks, Schegloff, \& Jefferson (1978) discussed the notion of "active listening", considering it necessary to participate in a conversation. McCarthy (2003) examined the same idea and emphasized the critical role of the listener in constructing intersubjectivity simply by being attentive to the other interlocutor.

The teacher's use of active listenership also results in topic expansion by the students, something that linguists such as Waring (2002) consider a crucial topic development move. It shows a great deal of understanding on the part of the students, as well as an ability to express themselves beyond the original topic. This reflects the students' interactional competence in L2 (Young,2013; Walsh, 2012). When used appropriately by the teacher, active listenership devices 
also support the students and present proof of the teacher's comprehension of what they have said, which leads to further participation.

\section{Repair}

The teacher's use of questions to help the students extend the topic under development results in multi-unit turns in which several interactional resources are used, including selfinitiated repair. When a breakdown in the communication occurs, the teacher refrains from using the less-preferred, other-initiated repair. On the contrary, she uses techniques such as clarification requests and confirmation checks to allow the students to carry out the preferred self-repair in the form of questions.

The students sometimes use L1 to establish mutual understanding, particularly when intersubjectivity is threatened or a communication breakdown occurs. The teacher, however, does not seem to object to this use. In fact, she encourages it by responding in L1. However, the use of L1 is abandoned once intersubjectivity is re-established, or the topic under development reaches a termination point.

\section{Extended wait time}

In this dataset, the teacher's extended waiting time results in some instances of postexpansion on the part of the students (Schegloff, 2007). The teacher in this data set tends to delay the feedback step in the traditional triadic IRF/E. In fact, she sometimes replaces the possible negative evaluation with a reformulation of the student's response. This is understood as a request for confirmation, as proved by the subsequent turn. This technique encourages the students to communicate freely without concerns regarding their linguistic competency.

\section{Topic management}

Generally speaking, the conversation in these data is goal-oriented, as it lasts for a long time once it begins, and the topic is maintained over a long stretch of talk. Regarding topic management, the teacher in this class maintains the original topic; however, because the topic is relatively free, the students can suggest new subtopics, and the teacher seems to encourage this. Nevertheless, the teacher signals the concluding move in each sequence and the shifts to the next one via the use of discourse markers and response tokens that indicate agreement or acknowledgment, followed by the allocation of the next speaker's turn. Despite this, the students play a highly active role in the development of the topics.

We also observed a great deal of mutuality and collaboration among the students and the teacher, particularly regarding topic development.

We noted the teacher's use of syntactic elements to link the turns and the tremendous sense of joint responsibility to maintain the interaction by all interactants. On the other hand, the teacher tended to use many open-ended questions to help the students extend the topic under development, thus increasing their interactional space.

The conversation was generally characterized by multiple subtopics related to the central theme, or those that mainly stemmed from the original topic suggested by the teacher in the opening move. 


\title{
Conclusion
}

This paper is a detailed microanalysis of a transcript of part of a reading comprehension classroom. The teacher in this data set takes the students a step further in their comprehension by announcing a new phase in which they are required to display understanding by applying the knowledge they have acquired from the reading passage to their own lives. What is interesting about this move is the teacher's ability to encourage students with limited linguistic resources to employ complex interactional competencies and to become fully engaged in the classroom discussion.

We present examples of how teachers can help their students develop a better understanding and display better interactional competencies by carefully utilizing different interactional resources. It is hoped that the result will help EFL/ESL teachers to attain a better understanding of CIC in EFL. It is also hoped that this paper will add to the body of work that has been done to conceptualize IC in institutional contexts, namely, the classroom.

The discussion in this paper also highlights the importance of CIC as an additional skill that should be introduced deliberately, in addition to other linguistic skills, in any EFL/ESL classroom.

Further, it is essential to discuss the role of teachers' awareness of their use of interactional resources and the implications of such use on their students' abilities to become better conversationalists (Eskildsen, 2021).

\begin{abstract}
About the authors:
Dr. Sabria Jawhar is an assistant professor of applied and educational linguistics at KSAU-HS. Dr. Jawhar is a graduate of Newcastle University, UK. She is interested in all aspects of classroom discourse, assessment and use of technology in HE. However, her main focus is on talk-in-interaction. Corpus linguistics, especially spoken corpora, is another area of her interest. https://orcid.org/0000-0002-1799-8888
\end{abstract}

Prof. Steve Walsh is Professor of Applied Linguistics at Newcastle University, UK, where he was, until recently, Head of Department. His research interests include classroom discourse, teacher development, second language teacher education, and professional communication. He has published 10 books and more than 100 research papers.https://orcid.org/0000-0003-45247827

Dr Sajjadllah Alhawsawi is an assistant professor of English as Foreign Language at KSAUHS. Dr Alhawsawi holds a PhD in education from School of Education and Social work, University of Sussex, UK. Dr Alhawsawi's research interest includes programme evaluation, teacher education, higher education, instructional design, sociology of education and pedagogical use of ICT university education. n. https://orcid.org/0000-0002-6175-9892 
Arab World English Journal (AWEJ) Volume 12. Number 4. December 2021

Going beyond the Text: Interactional Competence

Jawhar, Alhawsawi, \& Walsh

\section{References}

Brouwer, C. E. (2003). Word search in NNS-NS interaction: opportunities for language learning? The Modern Language Journal, 4 (87), 534-545. https://doi.org/10.1111/1540-4781.00206

Chomsky, N. (1965). Aspects of the Theory of Syntax. Cambridge: M.I.T Press.

Eskildsen, S. W. (2021). Doing the daily routine: Development of L2 embodied interactional resources through a recurring classroom activity. Classroom-based Conversation Analytic

Research: Theoretical and Applied Perspectives on Pedagogy, 71-101.

Firth, A. (1996). The discursive accomplishment of normality: On 'lingua franca' English and conversation analysis. Journal of Pragmatics (26), 237-259.

https://www.academia.edu/download/3241851/lingua_franca_and_conversation_analysi s.pdf

Firth, A., \& Wagner, J. (1997). On discourse, communication, and (some) fundamental concepts in SLA research. The Modern Language Journal 81(iii),. 285-300. https://doi.org/10.1111/j.1540-4781.1997.tb05480.x

Ford, C. E., and S. A. Thompson. (1996). "Interactional Units in Conversation: Syntactic, Intonational, and Pragmatic Resources for the Management of Turns." In Interaction and Grammar, edited by E. Ochs, E. A. Schegloff, and S. A. Thompson, 134-184. Cambridge: Cambridge University Press.

Galaczi, E., \& Taylor, L. (2018). Interactional Competence: Conceptualisations, Operationalisations and Outstanding Questions. Language Assessment Quarterly, 15 (3), 219-236. https://doi.org/10.1080/15434303.2018.1453816

Gardner, R. (2001). When listeners talk: Response tokens and listener stance (Vol. 92). John Benjamins Publishing.

Gardner, R., \& Wagner, J. (2004). Second Language Conversation. London, New York: Continuum.

Goodwin, C. (1980). Restarts, Pauses, and the Achievement of a State of Mutual Gaze at Turn-Beginning. Social Inquiry, 50(3-4), 272-302. https://doi.org/10.1111/j.1475-682X.1980.tb00023.x

Gregg, K. R. (2005). SLA Theory: Construction and Assessment. In C. Doughty, \& M. Long(Eds.), The Handbook of Second Langauge Acquisition. London: Blackwell Publishing.

Hall, J. (1999). A prosaic of interaction: The development of interactional competence in another language. In E. Hinkel(Ed.), Culture in Second Language Teaching and Learning (pp. 137-151). Cambridge: Cambridge University Press.

Have, P. t. (1999). Doing conversation analysis: A practice guide. London: Sage Publications.

He, W. A. (2004). CA for SLA: Arguments from the Chinese language classroom. Modern Language Journal,88 (iv), 568-582. https://doi.org/10.1111/j.0026-7902.2004.t01-19-.x

Heinemann, T., (2008). Questions of accountability: yes-no interrogatives that are unanswerable. Discourse Studies, 10, 55-71

Jawhar, S. (2018). The Use of L1 as a Source of Humour to Facilitate Interaction in EFL Classroom. Arab World English Journal, 9, 294-310. https://www.academia.edu/download/57467334/20.pdf

Jefferson, G. (1984). Notes on a systematic deployment of the acknowledgement tokens "yeah"; and "mm hm". https://www.tandfonline.com/doi/abs/10.1080/08351818409389201

Kasper, A., \& Wagner, J. (2011). A Conversation-analytic Approach to Second Language Acquisition. In D. Atkinson, Alternative approaches to second language acquisition (pp. 149-177).

New York: Routledge.

Kasper, G. (2004). Participant orientations in German conversation-for-learning. The Modern Language Journal, 88(4), 551-567.

https://www.tandfonline.com/doi/abs/10.1080/08351818409389201

Kim, K. (2017). Topic initiation in conversation-for-learning: Development and pedagogical perspectives. English Teaching, 72 (1), 73-103. http://journal.kate.or.kr/wpcontent/uploads/2017/04/04Younhee_Kim.pdf 
Arab World English Journal (AWEJ) Volume 12. Number 4. December 2021

Going beyond the Text: Interactional Competence

Jawhar, Alhawsawi, \& Walsh

Kramsch, C. (1986). From language proficiency to interactional competence. The modern language journal, 70(4), 366-372. https://www.jstor.org/stable/326815

Kurhile, C. (2006). Second Language Interaction. Amsterdam: John Benjamins.

Long, M. H. (2006). Problems in SLA. Second Language Acquisition Research Series. Lawrence Erlbaum Associates (Bks).https://eric.ed.gov/?id=ED493800

Mackey, A., \& Goo, J. (2013). Interaction Approach in Second Language Acquisition. The Encyclopedia of Applied Linguistics.

https://onlinelibrary.wiley.com/doi/10.1002/9781405198431.wbeal0551

Markee, N. (2015). The handbook of classroom discourse and interaction. John Wiley \& Sons.

McCarthy, M. (2003). Talking Back: "Small” Interactional Response Tokens in Everyday Conversation.

Research on Language and Social Interaction, 36 (1), 33-63. https://doi.org/10.1207/S15327973RLSI3601_3

Moorhouse, B. L., Li, Y., \& Walsh, S. (2021). E-classroom interactional competencies: Mediating and assisting language learning during synchronous online lessons. RELC Journal, 0033688220985274. https://doi.org/10.1177/0033688220985274

Nesi, H. (2012). Laughter in university lectures. Journal of English for Academic Purposes, 11, 79-89. https://doi.org/10.1016/j.jeap.2011.12.003

Nguyen, H. T. (2011a). Achieving recipient design longitudinally: Evidence from a pharmacy intern inpatient consultations. In J. Hall, J. Hellermann, \& S. P. Doehler(Eds.), L2 Interactional Competence and Development (pp. 173-205). Bristol: Multilingual Matters.

Nguyen, H. T. (2011b). A Longitudinal microanalysis of a second language learners' participation. In G. Pallotti, \& J. Wagner(Eds.), L2 Learning as a Social Practice Conversation-Analytic Perspectives (pp. 17-44). Honolulu, HI: University of Hawai'i, National Foreign Language Resource Center.

Ortega, L. (2005). Methodology, Epistemology, and Ethics in Instructed SLA Research: An Introduction. The Modern Language Journal, 89(iii),317-327. https://www.jstor.org/stable/3588660

Pekarek Doehler, S., \& Berger, E. (2016). L2 interactional competence as increased ability for contextsensitive conduct: A longitudinal study of story-opening. Applied Linguistics, 39(4), 555-578. https://doi.org/10.1093/applin/amw021

Pekarek Doehler, S., Wagner, J., \& Gonzalez-Martinez(eds). (2018). Longitudinal studies in conversation analysis. London: Palgrave Macmillan.

Reddington, E. (2018). Managing participation in the adult ESL classroom: engagement and exit practices. Classroom Discourse, 2 (9), 132-149. https://doi.org/10.1080/19463014.2018.1433051

Richards, K., \& Seedhouse, P. (2005). Applying Conversation Analysis. New York: Palgrave Macmillan.

Sacks, H., Schegloff, E., \& Jefferson, G. (1978). A Simplest Systematics for the Organization of Turn Taking for Conversation. In J. S. (ed), Studies in the Organization of Conversational Interaction (pp. 7-55). Academic Press.

Schegloff, E. A. (2007). Sequence organization in interaction: A primer in conversation analysis I (Vol. 1). Cambridge university press.

Schegloff, E., \& Sack, H. (1973). Opening up closings. Semiotica (8), 289-327. https://web.stanford.edu/ eckert/Courses/1562018/Readings/SchegloffSacks1973.pdf

Seedhouse, P. (2004). The interactional architecture of the language classroom: A conversation analysis perspective. Language Learning, 54(Suppl1), $x$-300. https://doi.org/10.1111/j.14679922.2004.00266.x

Seedhouse, P., \& Walsh, S. (2010). Learning a second language through classroom interaction. In P. Seedhouse, S. Walsh \& C. Jenks (Eds.), Conceptualising learning in applied linguistics (pp. 127-146). Palgrave Macmillan. 
Sert, O. (2015). Social interaction and L2 classroom discourse. Edinburgh University Press. Sert, O., \& Balaman, U. (2018). Orientation to negotiated language and task rules in online L2 interaction. ReCALL, 30 (3), 355-374. https://doi.org/10.1017/S0958344017000325

Sert, O., \& Walsh, S. (2013). The interactional management of claims of insufficient knowledge in English language classrooms. Language and Education, 27 (6), 542-565. https://doi.org/10.1080/09500782.2012.739174

Ten Have, P. (2007). Doing conversation analysis. Sage.

Walsh, S. (2006). Investigating Classroom Discourse. London: Routledge.

Walsh, S. (2012). Conceptualising Classroom Interactional Competence. Novitas Royal, 6(1),1-14. https://citeseerx.ist.psu.edu/viewdoc/download?doi=10.1.1.678.2695\&rep=rep1\&type= pdf

Walsh, S. (2013). Classroom Discourse and Teacher Development. Edinburgh: Edinburgh University Press.

Walsh, S., \& Li, L. (2013). Conversations as space for learning. International Journal of Applied Linguistics. https://doi.org/10.1111/ijal.12005

Waring, H. (2019). The what and how of English language teaching: Conversation analytic perspectives. In X. Gao (Ed.), Second handbook of English language teaching (pp. 1053-1070). Springer.

Waring, H. Z. (2002). Displaying substantive recipiency in seminar discussion. Research on Language and Social Interaction 35, 453-79. https://doi.org/10.1207/S15327973RLSI3504_3

Young, R. ( 2013). Learning to talk the talk and walk the walk: Interactional competence in academic spoken English. Ibérica 25, 15-38.

Young, R. (1999). Sociolinguistic approaches to SLA. Annual Review of Applied Linguistics, 19, 105132. http://hdl.handle.net/10497/13662

Zuengler, J., \& Miller, E. (2006). Cognitive and Sociocultural Perspectives: Two Parallel SAL Words? TESOL Quarterly, 40(1),35-58. https://doi.org/10.2307/40264510

\section{Appendix (A)}

A copy of the introduction to the lesson in the student's book.

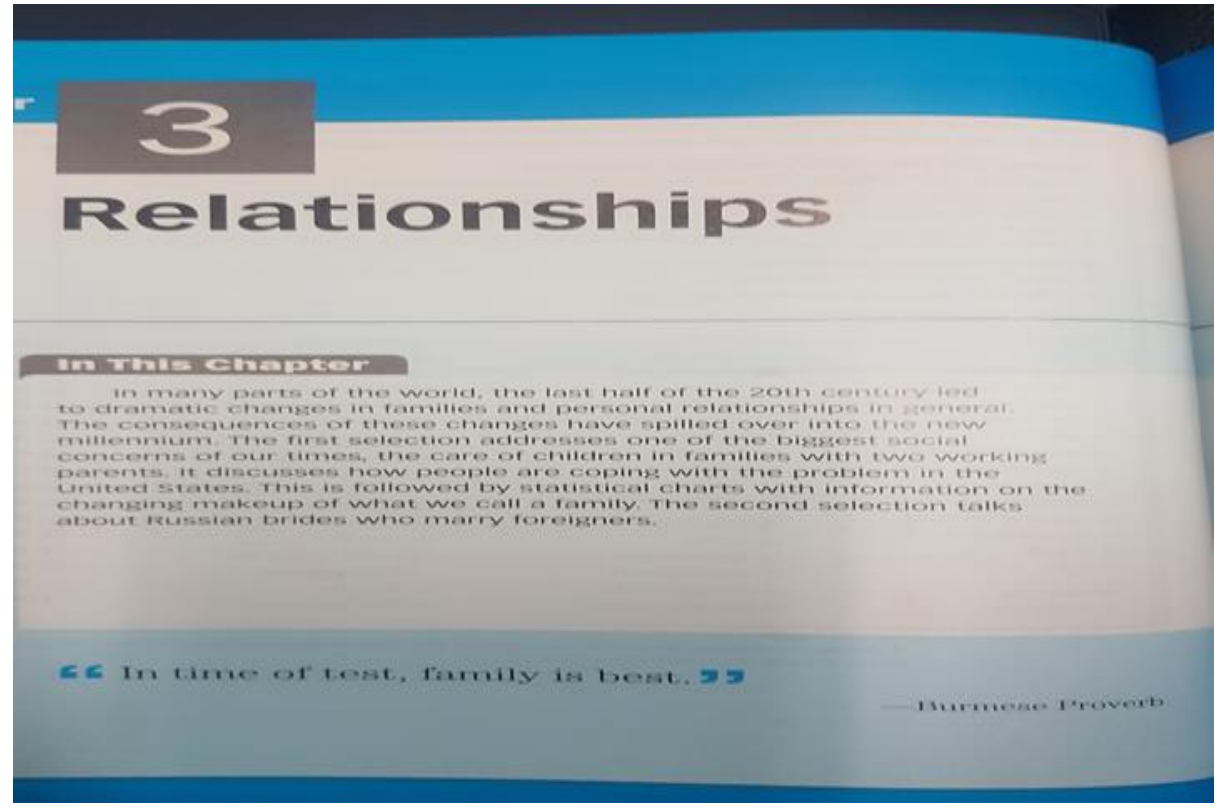

